\title{
Concentrate for Gargle Dosage Form
}

National Cancer Institute

\section{Source}

National Cancer Institute. Concentrate for Gargle Dosage Form. NCI Thesaurus. Code C149391.

Liquid preparation consisting of an aqueous solution intended to be diluted in water to obtain a gargle. 